\title{
Ignacio Ellacuría, voluntad de liberación
}

\author{
Luis Diego Cascante, \\ Instituto Teológico de América Central, \\ San José, Costa Rica.
}

\section{Prólogo}

La muerte calla muchas verdades. De mayor peso resulta esta afirmación cuando se trata de individuos cuya presencia ha marcado la historia de comunidades, pueblos e incluso naciones. Han sido personas que respondieron de manera inocultable a las exigencias de una historia sobre la que no sólo habra que escribir, sino que no pocas veces exigla la acción para generar el bien común, no sólo algunos bienes particulares. Y respondieron muchas veces en contradicción con los poderes de este mundo.

Los ideales que sin duda animan los discursos pueden quedar muchas veces en el anonimato debido a muchos factores, algunos comprensibles - personales, por ejemplo-, otros ni comprensibles ni mucho menos aceptables, como lo es el asesinato.

Es una dicha que Ignacio Ellacuría dejara escritos, y que otros tantos de sus amigos y colaboradores hayan asumido la tarea de publicar los que quedaron inéditos. Examinados sus escritos, el rigor teórico y el talante crítico son evidentes, y también se echa de ver con claridad qué es para Ellacuría el objeto de la filosofía: consiste en inquirir "el todo de la realidad dinámicamente considerado"1. Desde el dinamismo que otorga esta comprensión de la filosofía, Ellacuría afirma que la sustantividad humana se articula con la subjetividad, de modo que las notas de la realidad humana están enraizadas en una apropiación, al comprometerse de manera radical en crear posibilidades para todos. Por ello, la filosofra - también la teologra - debe vincularse a la política para iluminar lo mejor posible la época;

1. Ignacio Ellacuría, Filosofía de la realidad histórica, San Salvador, 1999, p. 25. 
o, lo que es lo mismo, para estar a la altura de los acontecimientos, aunque esto suponga tocar intereses particulares, que muchas veces buscan y controlan, subterráneamente, espacios y cuotas de poder, que se resisten.

Comprendida así la labor crítica y creativa de la filosofía, Ellacuría se adhirió a una filosofía afectada por la realidad, liberadora de nuevas formas de realidad, que pudiera responder a la pregunta de qué es el hombre y qué le conviene ser para seguir progresando como especie vinculada, constitutivamente, a sus "prójimos". Una filosofía así entendida, derriba ídolos, contribuye a develar lo que está de modo interesado encubierto, cuestiona de forma ineludible toda "ideología". No se niega lo especffico de la filosofía, pero se abre al diólogo interdisciplinar, en la búsqueda de alternativas.

Por lo que toca al problema actual -y de difícil solución- de la violencia, Ellacuría buscó humanizarla, y comienza - por honradez con lo real - reconociendo, sin escamotearlo, "lo terrible e inhurnano de lo que produce". Estuvo dispuesto a combatirla, pero no de forma violenta, sino asumiendo la causa de las víctimas, y prefiriendo medios que, en sí mismos, expresaran "la supremacía de la vida sobre la muerte" -como él decía - y de la solidaridad sobre el egoísmo. Finalmente, para que su opción fuera creible, se atrevió a actuar en consecuencia, aunque eso implicó morir en el empeño para liberar nuevas formas de realidad.

Basten estas palabras para comprender el móvil que animó radicalmente su vida y que lo llevó al compromiso indiscutible con un cristianismo liberador. Por eso, más allá de la radicalidad y frialdad intelectual, hay que destacar dos realidades que cofiguraron la persona del padre Ellacuría: su dogma inamovible y su fe inquebrantable. Es necesario conocerlos, si se desea comprender de forma adecuada sus pasionados discursos, sus análisis coyunturales, su metafísica de la realidad histórica, sus intuiciones teológicas, sus relecturas bíblicas y su propuesta política.

Pues bien, su dogma inamovible fue el dolor de los pueblos crucificados. Ellacuría volvió constantemente a ese tema. Fue, sin duda, hombre de compasión y de misericordia. Ese dolor puso a funcionar su privilegiada inteligencia y lo que encauzo su creatividad y su servicio. EI dolor de los pueblos crucificados se convirtió en su razón operativa. Proclamaba de modo insistente que hay que "bajar de la cruz a los pueblos crucificados". No sólo tuvo una privilegiada inteligencia, sino una inteligencia movida por la misericordia.

Y hay que mencionar también su inquebrantable fe en Dios. Inquebrantable porque, a pesar de la época en que le tocó vivir (los rodeos "trascendentales" de la modemidad), su inteligencia crítica y la gran pregunta por Dios que es, en sí mis$\mathrm{ma}$, la injusta pobreza latinoamericana, fue creyente. Quizás valga para Ellacuŕa lo

2. Jon Sobrino, "La redención de la violencia", Concilium, 272 (1997) 688. 
que él decía de su maestro Karl Rahner: "llevó con mucha elegancia sus propias dudas". Es decir, la fe no fue para él algo obvio, sino una victoria ${ }^{3}$.

Después de haber presentado de forma muy resumida el pensamiento y la realidad personal de Ignacio Ellacurfa, queremos analizar en este ensayo la relación que estableció entre filosofía y praxis, desde una metafísica de la realidad histórica -aunque hagamos también alusión a su pensamiento teológico. Ahondaremos, en primer lugar, en el significado profundo de la fórmula "cargar, encargarse y hacerse cargo" de la realidad, en su propuesta política y en el papel de la filosoffa, todo ello transido de la "voluntad de liberación". Al final, a manera de epílogo, resumiremos su pensamiento en forma de conclusiones.

\section{Cargar, encargarse y hacerse cargo de la realidad}

El método de Ellacuría se puede sintetizar', con un ingenioso juego de palabras, en estas tres tareas:

- Hacerse cargo de la realidad: conocerla real y vivencialmente, sufrirla visceralmente, para así poder descubrirla intelectualmente.

- Encargarse de la realidad: asumir la tarea de transformarla, poniendo la inteligencia al servicio de la praxis.

- Cargar con la realidad: aceptar la responsabilidad ética de la función intelectual y la dureza de esta confrontación.

El encargarse y el cargar con la realidad exige, automáticamente, una ética: la honestidad con lo real y la fidelidad a lo real. En Ellacurfa, esto debe cumplir también la teología historizada (pues es en la historia donde se actualizan las máximas posibilidades de lo real, en concreto, la posibilidad de una progresiva liberación integral de la humanidad), la cual no sólo debe hacer avanzar el conocimiento, sino que debe encargarse de la realidad. El reino de Dios tiene que ver, en definitiva, con una "historia trascendente o una trascendencia histórica en paralelo estricto con lo que es la vida y la persona de Jesús, pero de tal forma que es la historia la que lleva a la trascendencia, ciertamente porque la trascendencia de Dios se ha hecho historia, ya desde el inicio de la creación"s. En otras palabras, hay que actualizar la utopía cristiana, ya dada, desde la interpelación (signos de los tiempos), que va manifestándose por el Espíritu, a lo largo de la historia.

3. Para el tema de la fe en Ignacio Ellacurfa, véase el artículo de Jon Sobrino, "Monsenoor Romero y la fe de Ignacio Ellacuría", Revista Senderos, 69 (2001) 409-425.

4. Cfr. Víctor Codina. "Ignacio Ellacuria, teólogo y mártir", Proyecto, 33 (1999) 12-13.

5. Ignacio Ellacuría, "Utopía y profetismo", en I. Ellacuría y Jon Sobrino (eds.), Mysterium Liberationis, Vol. I, San Salvador, 1993, p. 396. 
La honestidad con lo real movía a Ellacuría a conocer, siempre en mayor profundidad, la realidad del pueblo salvadoreño (discernimiento). La analizó a la luz de la sociología y la política, y vio en ella una realidad radicalmente injusta: el capitalismo favorece a unos pocos, no es universalizable, ni ofrece soluciones para la humanidad. En conceptualización cristiana, esa injusticia es pecado, porque crucifica al pueblo, queriendo establecer una civilización de la riqueza. Configurada por ese capitalismo. la política hace brotar una clase política plagada de corrupción. El capitalismo es, entonces, irreformable por ser esencialmente anticristiano ${ }^{6}$.

La fidelidad a lo real le movió a cargar con la realidad, a fin de construir un nuevo orden histórico internacional, y en el que el pueblo de Dios sea sacramento de Cristo. Es en la historia, entonces, donde se juega la salvación: no sólo existe una historia de la salvación, sino que debe existir una salvación en la historia. Y la fundamentación última es que el Dios cristiano no es trascendente al mundo, sino trascendente en el mundo. De ahí que si existe alguna posibilidad de acceder a El, ésta tiene que ser en el mundo. Por último, frente a la política - de la compción-, Ellacuría acentúa lo social, la concientización popular previa al cambio de estructuras. Y ése era para él el papel que debía juagar la universidad, la $\mathrm{UCA}^{7}$. De esta forma pueden los seres humanos encaminarse hacia y construir la tierra nueva de la utopía cristiana.

Para terminar este primer apartado, permítaseme hacer dos breves disgresiones, relacionadas con nuestro tema.

La primera es sobre algunos aspectos de la concepción de Ellacuría acerca del reino de Dios y su relación con la Iglesia. En 1984 publicó, en España, su texto Conversión de la Iglesia al reino de Dios". En este texto, sostiene que debemos promover un nuevo orden, es decir, que "todos tengan vida y la tengan en abundancia" (Jn 10, 10). Esto implica que el reino de Dios es más bien un reinado, "una acción pernanente sobre la realidad histórica", y la Iglesia es la que tiene la garantía auténtica de la historia de la salvación, que consiste en "mirar el entomo con ojos de pobre", para encontrar a Jesús, donde El dijo que estaba. Esto obliga a historizar la inteligencia para estar en comunicación con los seres humanos y en comunión con su condición humana ${ }^{10}$. La Iglesia puede y debe auscultar y seguir

6. Tanto al "proyecto" de Estados Unidos, en cuanto ambicioso y sin escrúpulo -además de miope, incapaz e inepto-, como al de los gobiernos militares y oligárquicos, que utiliza la fuerza bruta, al de los paramilitares, siempre sembrando muerte por doquier, y al de la guerrilla con sus engaños, hay que "redimirlos de la violencia".

7. Cfr. Ignacio Ellacurfa, Veinte afios de historia en El Salvador (1969-1989). Escritos polfticos. Vol. I, San Salvador, 1993, pp. 17-46.

8. Santander, Sal Terrae, 1984.

9. Ibrd., p. 16.

10. lbid., p. 224. 
signos variados, pero signos que no son elegidos por el hombre - para evitar la arbitrariedad-, sino la biografía de Jestís, de modo que éste tome cuerpo en la historia, "en una transformación de la historia que prepare el estallido de la gloria de Dios". Para esto hay que cuidarse de no caer en dos peligros:

1. La ética de los múnimos y de la religiosidad superficial, para no convertir la historia de la salvación en algo intimista-subjetivista. Si así fuera, nos acercaríamos a una contradicción entre la institución y el espíritu cristiano, con el peligro de asumir formas de espíritu y de espiritualización, que no son gracia.

2. Leer la historia de la salvación, en clave secularista-politizante. A nadie conviene que la Iglesia sea una "opción polf́tica", dada la crisis de las instituciones. Como institución podría caer en el institucionalismo, que mata el espíritu de Jesús, que la anima y que, a su vez, la libra de toda concreción secularista, que la alejaría del sentido profético, en medio de la realidad que le toca vivir.

Ambas maneras de entender la Iglesia no la configuran según Jesús, pues se une a los poderes de este mundo para subsistir como institución, estando así en connivencia con la siruación social de pecado, que puede llevar a algunos bienes, pero no al bien común. Esto es, lleva a una falsa mundanización y corre la tentación de fosilizarse. En consecuencia, la conversión de la Iglesia al reino debe incluir. a) que la Iglesia sea vista desde la perspectiva del reino de Dios (negación de la mundanización); b) que el pueblo de Dios, lugar teológico por antonomasia, sea el pueblo de los "pobres con espíritu", para que así sea la Iglesia del pueblo; c) que su carninar sea profético, y sea así sacramento histórico de liberación, como lo fue Cristo.

La segunda disgresión versa sobre la realidad más profunda de la pobreza. La pobreza ha dado lugar a muchísimos estereotipos, pero cuando se habla de "pobres" se debe entender, ante todo, aquellas personas que no tienen ni siquiera un dólar para satisfacer sus necesidades básicas diarias y que, por estar en condiciones "imposibilitantes", les resulta imposible superar dicha situación. Es cierto que existen varias situaciones imposibilitantes, pero la pobreza es la madre de todas ellas, pues sumerge al individuo en un círculo vicioso: el pobre no encuentra salida para recuperar los elementos materiales que le posibilitarían vivir mejor $y$, por ende, termina viviendo peor.

La pobreza implica una vida de privaciones y de exclusiones de los medios para vivir mejor. No se trata de una pobreza derivada, sino resultante, pues depende de las acciones de otros individuos; es superable y es, por ello, dolorosa. No es ley natural, sino que emerge de la falta del intercambio justo. Tal vez se podría pensar que la solución radica en arrebatarles a unos para que otros tengan. Pero esto sería una mala solución, pues la movilidad social no sería, en ese caso, signo de la superación del problema. Más bien, indicaría inconsistencia, de parte de quienes abogan por una sociedad equitativa. 


\section{Crílico de la política y constructor de la paz}

\subsection{Hacerse cargo de la realidad}

Ellacuría siempre tuvo alergia a las recetas políticas. Más bien, creyó que se debe estar a la altura de los tiempos y responder a ellos, lo más adecuadamente posible, buscando siempre dos cosas: saber la verdad de lo que en realidad ocurre y conseguir una paz justa, fruto de la negociación, que en su tiempo la relacionó con lo que él llamó la "tercera fuerza". Así, buscó hacerse cargo de la realidad.

En la "democracia" vio, ciertamente, valores y derechos dignos de consideración, si se llevan hasta sus últimas consecuencias y se generan las condiciones reales para su disfrute. Pero "lo que busca el manejo ideologizado del modelo democrático no es la autodeterminación popular respecto del modelo político y económico, sino el encubrimiento de la imposición capitalista"'11, de manera que la democracia es apoyada, en la medida en que favorezca esos intereses. Por ello, defendió que se deben buscar nuevos caminos en la historia, dado que estamos mal y que nos ofrece una mala solución: el capitalismo con su civilización del capital.

En términos generales, el capitalismo liderado por Estados Unidos (según el gobiemo de tumo) tiene, principal, aunque no exclusivamente, una especifica razón de ser: no busca una solución política a los conflictos de los pueblos, sino la conquista del poder. Para ahondar en esta crítica, hay que verla desde dos perspectivas: la relación de Estados Unidos con los países -económica y militarmente- desarrollados, y la relación de Estados Unidos con los parses -económicamente- subdesarroliados.

Por lo que toca a lo primero, el capitalismo de Estados Unidos fomenta, en primer lugar, la sospecha y busca saber qué están haciendo los demás: espionaje; y en segundo lugar, busca el equilibrio - que llama democracia-, exhibiendo su potencial militar y la necesidad de medidas urgentes (la guerra, por lo general) para que se conserve la situación actual. Por lo que toca a lo segundo, el asunto cambia. El liderazgo de Estados Unidos - compartido con otros directa o reservadamente - mantiene la vieja práctica de crear expectativas de riqueza, en los pueblos que emergen, e inyectarles democracia. Pero detrás de las ofertas se encierra, de hecho, un proyecto polf́tico y económico, que contradice el ofrecimiento generoso.

Todo lo anterior es posible porque Estados Unidos muestra un rostro democrático dentro de sus fronteras, pero lo puede hacer gracias a que, en el plano intemacional, su posición es antidemocrática - verticalidad política. Esto quiere

11. I. Ellacurfa, "Utopía y profetismo", p. 406. 
decir que la democracia no es un valor universalizable. En otras palabras, el régimen polf́tico que permite esta doble moral, en términos económicos, es, precisamente, la democracia, pues, bajo la apariencia de pluralismo y tolerancia, se torna intolerante con quienes no hacen aquello que están forzados a hacer.

La conclusión es que la solución estadounidense - y de quienes la avalan - es una mala solución, a corto y largo plazo, porque no es universalizable para todo el mundo. Es, entonces, una solución inhumana. Es la inhumanidad que genera, entre otras muchas cosas, paz, a cambio de amenazar con la guerra; riqueza, a cambio de que el ochenta por ciento de la población mundial viva en pobreza extrema, sin tener ni siquiera lo básico para vivir, además de la devastación ecológica que produce la explotación de los recursos sin medir la destrucción, etc ${ }^{12}$.

Sin embargo, según Ellacuría, no sería acertado echar la culpa de todos los males - latinoamericanos - a los otros, "porque tal exculpación legitima o encubre comportamientos y acciones del todo condenables, ya que los sistemas, los procesos, los dirigentes, no por ser dependientes, dejan de asumir y aun potenciar los males de la dependencia"l3. Ese es el caso, por ejemplo, de la deuda externa (eterna), pues los préstamos, que dieron origen a la deuda, se hicieron con frecuencia de forma poco equitativa y con la complicidad de gobiernos y clases sociales, sin provecho alguno para las mayorías.

La conclusión es que hay que construir una nueva civilización, la civilización de la pobreza ${ }^{14}$, que no es sino una civilización del trabajo, y que se caracteriza por una vida austera y solidaria, en la cual los recursos se orienten a satisfacer, ante todo, las necesidades básicas, en lugar del consumo; a compartir, en lugar del disfrute alienante, a una cultura comunitaria y festiva. Los profesionales responsables deben trabajar en esta dirección.

\subsection{Cargar con la realidad}

Cargar con la realidad significa cargar con las cosas y con lo que ellas exigen. Eso es ser realistas. En consecuencia, se debe religar la ética a la política, como lo sostuvo Francisco Suárez ${ }^{15}$, para lograr un resultado aceptable para la humanidad, y para ello, hay que revertir una comprensión del poder como algo autónomo, centrado en sí mismo, narcisista. En palabras de Ellacuria, hay que promover "un proyecto global que sea universalizable". La universalidad está directamente asociada a un compromiso en favor de lo que podria llamarse "bien co-

12. Cfr. I. Ellacuría, “Descubrimiento o encubrimiento?", Revista Senderos 40 (1989) 99-114.

13. Cfr. l. Ellacuría, "Utopía y profetismo", pp. $401-402$.

14. Cfr. I. Ellacura, "Las Bienaventuranzas, carta fundacional de la Iglesia de los pobres", en Conversión de la Iglesia al reino de Dios, Saı Salvador, 1985, pp. 129-151,

15. De legibus III, c. XX, n. 11. 
Inún". Pero para que esto suceda, urge una "repolitización" de la vida ciudadana, que haga protagonistas a los integrantes de las comunidades, a la hora de las decisiones que construyen la vida social y que a todos afectan ${ }^{16}$. La consecuencia inmediata es que "hay que desprivatizar la ética", trascendiendo así el ámbito de lo privado (la familia, el trabajo, el consumo). Los canales hasta ahora utilizados son altamente institucionalizados. En su momento ofrecieron beneficios, pero ahora se encuentran desgastados. El viejo Estado de derecho ha de constituirse en estado de justicia, si quiere ser viable para la humanidad.

Y se entiende, entonces, que, frente a la "civilización del capital", que reza "más mercado, menos Estado", se debe defender la "civilización del trabajo", no para producir capital, sino para desarrollar la humanidad. Sólo revirtiendo la historia y ubicando al hombre en su centro, la humanidad encontrará soluciones apropiables para todos y cada uno.

En medio de una realidad de violencia, hay que añadir que no se puede construir la paz sin conocer la verdad; no se puede conocer la verdad sin la reconciliación; y no puede haber reconciliación sin el perdón.

\section{Encargarse de la realidad. Filósofo de la praxis y "praxis liberadora"}

Ellacuría vio en la filosofía un remedio para los males de la realidad: la filosofía dialoga, propone las cuestiones de manera abierta para propiciar una praxis liberadora, una praxis que es creación humana (capacidad) y lleva a la liberación de nuevas formas de realidad.

La función liberadora de la filosofía incluye el concepto de historización como método para remediar los desvios - que por cierto, son legión- de la ideologización. La ideologización, entendida como abstracción de la realidad histórica, desvincula los conceptos y teorías de su contexto histórico. Por su parte, la historización es "una crítica liberadora de ideologizaciones" (H. Samour) y, como tal, es parte integrante de la actividad critica de la filosofía. Por ello, la liberación, siempre historizada, es creadora de nuevas formas de realidad, es praxis.

El dinamismo al que apunta la filosofía zubiriana lleva, tal como lo expone Ellacuría, a asumir la historia como plenitud de lo real ${ }^{7}$, lo cual se puede resumir en tres tesis que desarrollamos a continuación.

16. Ellacuría siempre lo defendió, pues la liberación tiene que ser de rodos y cada umo. Por ello buscó influir en la configuración de la opinión pública, tanto a nivel nacional como intermacional, en la construcción de la paz, en particular, en El Salvador, que le tocó vivir y que amó hasta la muerte. Esta es la tercera fuerza: ser voz de los sin voz, y de quienes los profesionales de la política se dicen voceros sin escucharles. La tercera fuerza es una "dinámica negociadora" (M. Montobbio).

17. Ignacio Ellacuria, Filosofia de la realidad hisiorica, San Salvador, 1999. 


\subsection{La historia con apropiación de posibilidades}

La realidad histórica es apropiación de posibilidades, en donde ninguna de las posibilidades históricas se autosostiene, sino que remite a una base material, biológica, social y económica muy determinada.

En primer lugar, y sin caer en un continuismo puramente biológico, la materialidad de la historia indica la imposibilidad de que se dé la historia sin naturaleza, sin "salto cualitativo alguno". En este sentido, la historia es ya un proceso de liberación, en relación a la naturaleza, pero de ninguna manera su negación ${ }^{18}$. Es la liberación del estímulo para aprender y enfrentar las cosas como reales. Lo dicho pone en evidencia la materialidad de la historia - no se confunda con el materialismo histórico. El trabajo, entonces, es "acción transformadora por la cual se domina el medio y se libera la vida humana". Es el carácter biológico del trabajo y, a la vez, su carácter histórico, abierto. Es el trabajo visto como principio de liberación personal y social. Mas no se crea de modo ingenuo que el trabajo, por ser lo que es, necesariamente libera. La sociedad actual convierte el trabajo, en cuanto liberación, en obligación. Se establece así una dependencia que varía, según el tipo de trabajo, el estrato social e incluso el grado de automatización, etc. El trabajo como obligación-necesidad empequeñece a la persona, pues ésta no puede apropiarse de las posibilidades. No opta por ellas, sino que le sobrevienen, lo atropellan, lo aplastan, sin dejar espacio para construir su proyecto ${ }^{19}$.

18. Filosofía..., p. 207.

19. Hagamos un breve comentario desde la crítica del economista Franz Hinkelammert. Parece que lo primero que debe discutirse es la presunta libertad de todos y cada uno de los que participan en el sistema económico, que inyecta democracia por doquier. Necesario es pensar un poco en ello. En principio, el pensamiento neoliberal tiene una motivación: evitar la superación de la sociedad burguesa por la sociedad altemativa. La sociedad a la que nos referimos tiene como centro una institución: el mercado. El pensamiento central gira en torno a la precariedad del mercado. "El mercado funciona en cuanto está en equilibrio; la preocupación política. por tanto, tiene que ser lograr que esté efectivamente en equilibrio". Esta economía trató la razón instrumental como autosuficiente. lo que la obligó al análisis concreto. Los modelos que sigue son de corte platónico y, si se quiere, abitrarios. Sólo se acerca a la realidad de manera restringida. Se habla, pues, de un equilibrio general, que genera un doble problema: los presupuestos teóricos, que posibilitan el equilibrio, y los mecanismos sociales, que permiten la aproximación a ellos. El inconveniente del primero es que no se tiene ni se tendrá un conocimiento perfecto y, por tanto, el equilibrio resulta incalculable. Respecto de lo segundo, y consecuencia de lo anterior - supone que el mercado emplico hará una aproximación a este equilibrio idealizado-, las condiciones son de carácter empírico. Esto es, consisten en libertad de contrato y la garantía de la propiedad privada. Se idealiza un fenómeno empírico, que se presenta como cercano a la realización del ideal. Ante la inconsistencia teórica, se afirman, de manera irrestricta, las leyes del mercado $y$, desde luego, el carácter anti-intervencionista. Esto simula la 
En segundo lugar, se sigue también el componente social de la historia. Ser un individuo de un phylum determinado, modula las relaciones entre los individuos. Formalmente, la situación primaria de todo individuo humano es una cosituación, y su vivencia primaria es una co-vivencia ${ }^{20}$. Esto se muestra en el desamparo del niño, que se encuentra a sí mismo como vertido, de manera indigente a los otros. Es la publicidad de lo social. Esta versión con-vivente no está fundada en ideales, ni en comunicación de personas, sino en la propia realidad psicoorgánica. Pero a nuestro desamparo se le une la tragedia de un mundo cada vez más frenético, en relaciones sociales, en detrimento de nuestras relaciones personales. Esto implica que la sociedad es, constitutivamente, impersonal, en alteridad. Como tal, apunta Ellacuría con lucidez, la vida social no es vida humana, sino que es algo intermedio entre la naturaleza y el hombre, es una cuasi-naturaleza, y, como la naturaleza, irracional, mecánica y brutal ${ }^{21}$.

En tercer lugar, el carácter personal de la historia involucra a cada ser humano como individuo, individualidad que puede ser vista en tres sentidos: a) como la individualidad propia de lo real, propia de toda realidad; b) como la individualidad propia de la realidad personal, propia de toda persona, y c), finalmente, como la individualidad de una persona humana respecto de otra persona humana, esto es, la individualidad diferencial. En lo que hay que insistir es en que el carácter de individuo lleva a una diversidad que en nada niega el sentido positivo de la alteridad. Los "otros" intervienen, constitutivamente, en mi vida, y, de alguna manera, están constituyéndome, pues comparten situaciones conmigo. Lo que existe es una con-vivencia.

Sólo dentro de la colectividad humana es posible una relación intraindividual: la colectividad, es decir, el que uno depende de otro, es la solidaridad. Desde el inicio, las personas son nuestros próximos, prójimos. Se entiende, pues, la familia como lo primario, en el ámbito de la proximidad de las personas compenetradas - sin distancia -, donde se va imprimiendo positiva y negativamente la realidad de las personas. Ahora bien, vivir la con-vivencia con los demás significa que la vida de cada uno se vuelve inalienable. Es propia la versión a los demás, en virtud de lo cual, cada quien se ve modalizado, es decir,

carrera imposible que persigue un fin infinitamente lejano por pasos finitos, todo lo cual supone que, en la competencia perfecta, nadie compite. Pero como la competencia perfecta no existe, la tendencia al equilibrio resulta ser la solución.

Para que se dé el equilibrio, se requiere de un "salario de subsistencia", o lo que es lo mismo, los indicadores mercantiles y los precios relativos terminan siendo la pauta. El slogan de M. Friedman sintetiza esta postura: "libres para elegir". La variabilidad de los salarios se explica porque las preferencias subjetivas determinan lo que es consumible, ya que no hay necesidades, sino gustos y, como los gustos fluctúan, así también fluctúan los salarios.

20. Filosofia..., p. 209.

21. Filosofia..., p. 278. 
"frente a otro". Así es como cada uno, real y físicamente, es "cada cual". Y es que la vida de cada cual es inapropiable en toda su plenitud. Y es radicalmente inapropiable, pues la apropiación, formalmente dicha, lleva a la desaparición del otro. A partir de lo anterior, mi persona está vertida a los demás, como absolutos, en una co-determinación que es, justo, la dimensión, como modo de mi ser absoluto. Este proceso, en cuanto tal, sucede de forma prospectiva, en un proceso histórico.

En cuarto lugar, está la estructura temporal de la historia. Ni el ser humano es pura naturaleza, ni pura historia. Es una autoposesión transcurrente la que funda la temporalidad humana, e, indudablemente, en el nacimiento, en cuanto hecho biológico, es donde empieza el tiempo humano. En efecto, hablar de autoposesión es sinónimo de liberación: una serie de nuevas funciones - desde ciertas estructuras estabilizadas - permiten al viviente una mayor autonomia, la cual, por la forma inconclusa de las tendencias que funda, da paso a una forma más elevada de liberación, aquella por la que aparece la libertad. Libertad es futurición, y la futurición del hombre es una de sus máximas posibilidades. Y agrega Ellacuría: "Hombres sin futuro, pueblos sin futuro no son hombres ni pueblos, a los cuales no espere ningún después; son hombres y pueblos incapaces para futurizar, incapaces para romper el ritmo de la sucesión, de la edad y de la duración para recomponer la marcha del tiempo, para dar otro tiempo al tiempo"22. El problema es que se cercenan los medios para futurizar, y luego se les arrebata la esperanza, que era lo único que les quedaba. No se puede ni romper, ni recomponer la marcha. Es un destino, una civilización - la del capital-, que prima la explotación, y que, desde luego, resulta enajenante por sí misma y por lo que tiene de ideologica. Es cerrar el tiempo. Por ello, se debe revertir la historia.

En quinto lugar, está la realidad formal de la historia. Qué sea la historia en cuanto historia nos lleva a comprenderla como un proceso de apropiación de posibilidades, desde la tradición tradente, de modo que ella, en cuanto tal, no es un proceso de maduración o de desvelación, sino un proceso de capacitación. Es un proceso físico y metafísico de capacitación. La historia actualiza posibilidades y crea capacidades. Aparece ahora lo que Ellacuría llama el elenco de fuerzas históricas, las cuales pueden describirse así:

a) Las fuerzas estrictamente naturales. La historia tiene estructura corpórea, en cuanto forma de materia, que todavía no ha accedido a la vida.

b) Las fuerzas biológicas. La historia tiene, como se ha visto, un carácter biológico de modo que, pretender mostrarla sin ese carácter, tiene incalculables consecuencias prácticas, y promovería pseudoantropologías.

22. Filosofia... p. 437 
c) Las fuerzas psíquicas. No son independientes de las anteriores, pero representan algo cualitativamente distinto. Las fuerzas psíquicas son aquellas que radican en determinadas condiciones psíquicas de los individuos: "su talento, sea éste especulativo, organizativo, político, etc.; su ambición, su capacidad de arrastre, etc.". No cabe duda que personajes como san Juan de la Cruz, Mahatma Gandhi o Juan XXIII han creado posibilidades históricas.

d) Las fuerzas sociales son las fuerzas del cuerpo social. Mencionemos a manera de ejemplo, la estratificación social, los grupos de presión, la diferenciación ocupacional, toda la gama de costumbres y de usos recibidos, los prejuicios sociales, las modas, etc. De manera especial deben mencionarse las fuerzas económicas, que son los métodos a través de los cuales los seres humanos de una determinada sociedad producen sus medios de subsistencia e intercambio de productos, y que ahora, más que nunca, desempeñan un papel preponderante, en el modelo que se dice globalizable, mas no universalizable.

e) Las fuerzas culturales o ideológicas. Para bien o para mal, los seres humanos hacen su historia no con una voluntad colectiva o plan colectivo. Estas fuerzas no son explícitas, pero no por ello son menos eficaces. En nuestros días, primero se enfatiza el tener sobre el ser. Actualmente, no se es ni siquiera lo que se tiene, sino que nuestra relativa dignidad queda condicionada por la capacidad de consumo de cada uno.

f) Las fuerzas políticas, dependientes de las sociales y económicas, técnicamente se confunden en su funcionamiento. Podría decirse que las fracciones que ejercen el poder lo hacen con tal de asegurar su cuota, a través de una densa red de relaciones entre grupos y clases, por un lado, y los medios de poder, por otro. Estas, las fuerzas políticas, dan vida a un determinado modo de producción.

g) Las fuerzas estrictamente personales son aquellas que se generan en virtud de un acto de opción, sea de un individuo, sea de un grupo.

\subsection{El proceso histórico y la praxis}

El proceso histórico no consiste en desarrollo, sino en praxis ${ }^{23}$. La praxis no es, como señala Héctor Samour ${ }^{24}$, "un mero hacer consciente y libre", sino un "hacer real de la realidad", pero reconociendo que, a la par de esto, la liberación implica una "liberación de nuevas formas de realidad". Asumir las posibilidades apropiables, que remiten a una praxis, nos vierte hacia una actitud obstinada, que reconoce que "esto vale la pena". Y es que la realidad tiene su propio peso y, por ello, su propia exigencia (Julio Lois). En este sentido, tener pasión por la realidad significa que, en las posibilidades apropiables favorables - constitui-

23. Cfr. Antonio González Fernández, http://www.servcioshoinonia.org/relat/022.htm

24. "Filosoffa y libertad", p. 105, en Jon Sobrino y Rolando Alvarado, Ignacio Ellacuria. aquella liberiad esclarecida. San Salvador, 1999. 
das, en cuanto capacidades, en el principio histórico de lo humanarnente posible - se vaya más allá de las limosnas a las víctimas del mal, pues "la pobreza no es buena en sí misma"2s. Es necesario historizar la inteligencia para salir bien librados del horizonte del pensamiento dominante, que encubre y falsea la realidad. Encubre porque no deja que la realidad dé lo mejor de sí, y falsea, en tanto escamotea la verdad real. La praxis, ellacurianamente hablando, es liberacion que crea o una creación que libera la realidad.

La liberación debe contener una mayéutica histórica, en la que la inteligencia lleve al ser humano a tomar conciencia de su propia historicidad, "de sus concretas vinculaciones" en la práctica transformadora social "de la que surge, a la que sirve y en la que se mueve, pues solamente a partir de esta conciencia de propia situación es posible pretender la objetividad y una universalidad situadas"26. La consecuencia que se sigue obliga a pensar en la historización de la inteligencia para cambiar el significado del término libertad como libertad de la economía; una libertad política que promueva la liberación de los individuos de una política que no ejercen, ni controlan; una libertad intelectual que muestre la realidad tal como es, y lo que ésta impide que sea, para promover nuevas vías que, a la vez, ofrezcan, desde la creatividad, posibilidades apropiables para todos y cada uno, y no simplemente para unos pocos, que se sienten lejanos -y no prójimos - de las mayorías sufrientes, victimizadas.

Contemporáneamente, la democracia, desde luego, no significaría unanimidad - propia de los regimenes totalitarios -, sino "reconocimiento de la oposición" - no de la confrontación-, es decir, de la negociación ${ }^{27}$. En esto cabe hablar de un pecado histórico, junto al pecado original y personal, que se expresa en formas concretas, en cuanto factor teológico de la historia, según los tiempos... y que no es sino un ateísmo de la historia, lamentablemente de parte incluso de quienes se dicen creyentes, y tras cuya riqueza material visible se oculta la miseria de los valores y de los humanos ${ }^{28}$. Este realismo radical obliga a que toda

25. Tomás de Aquino, Suma contra los gentiles, III, 134, México, 1985. Trad. de Carlos Ignacio González, S.J.

26. José A. Gimbernat y Carlos Gómez, op. cit., p. 324.

27. La democracia actual proclama a gritos las libertades formales. Lo lamentable es que, dentro de ellas, las constituciones permiten desartollarlas sólo a quienes tienen las condiciones reales para poder hacerlo. Quizás habrfa que señalar otra de las contradicciones de la democracia, es decir, que, para evitar la guena, amenaza con ella.

28. La dimensión teologal del mundo creado estriba en esa presencia de la vida trinitaria, que es intrínseca a todas las cosas, y que en el hombre radica en poder aprehenderse como real y como principio de personalidad Cuando este dinamismo queda limitado, ya no en la evolución natural, sino en el proceso histórico - personal y social-, de forma deliberada, se absolutiza el límite, impidiéndolo, aunque no destruyéndolo, se está formalmente ante el pecado. Es la absolutización absoluta de lo que es sólo relativamente absoluto. Cfr. I. Ellacurfa, "Historicidad de la salvación cristiana", en I. Ellacuŕa y Jon Sobrino (eds.), Mysterium Liberationis, Vol. 1, San Salvador, 1993, pp. 358-359. 
propuesta de valores asuma de forna radical, la inalienabilidad de la vida como criterio fundamental, aunque tenga conciencia de la historicidad, y por supuesto, de la'tarea de desvictimizar a las víctimas, en aras de hacer cualquier proyecto humano realizable en la historia, es decir, que realmente contribuya a la sobrevivencia de la especie. Sólo la renuncia - a ser victimarios-, la denuncia - de lo que victimiza - y el anuncio - de la liberación - pueden salvarnos.

La liberación enfrenta, como saber crítico creativo, el reto de desideologizar los discursos y de develar la realidad, pues el único compromiso es con la realidad. La liberación, entonces, se asocia al saber. "El saber y el saber acomodado a una determinada situación social son una necesidad perentoria de la sociedad y de su liberación; los pueblos que no saben, las clases sociales que no saben, están condenadas a la opresión, a la explotación o, en el mejor de los casos, a la explotación espontaneísta y al fracaso asegurado"29. Ellacuría se refiere aquí al papel que le corresponde desempeñar a la universidad (o centro de formación intelectual) como agente autónomo, que desenmascara las ideologizaciones -entendidas ya como falsedades, ya como injusticias-, que hacen aparecer el proyecto imperante como el mejor. La autonomía se considera aquí no como un privilegio, sino como una necesidad histórica.

El quehacer filosófico accede a la realidad no por el camino de la abstracción sin más, sino por el camino de la máxima concreción. La realidad histórica revela la realidad total. En la historia es donde la realidad va dando de si y, por ende, resulta, en grado más intenso, política. Para no caer en ingenuidades, hay que reconocer que la filosofía no es la única instancia en este proceso, pero sigue siendo insustituible. Esto último se basa en que la filosofía es una praxis liberadora, no sólo de corrección ética, sino, además, de creatividad, siempre que se participe en ella con rigor teórico y distancia crítica.

\subsection{El sujeto de la historia}

Si la praxis es irreductible, "la historia no se puede entregar en manos de algún macrosujeto, sea la naturaleza, la razón o el Espíritu. La humanidad ha de permanecer como sujeto de la historia" ${ }^{30}$. Los seres humanos son, entonces, agentes, actores y autores de la historia y en la historia, sin que se hable ya de sujeto-acción. En este sentido, esta tesis nos remite a la eticidad, pues pone la historia en manos de la humanidad, en su conjunto, para ejercer un control racional y democrático, $o$, lo que es lo mismo, para generar liberación.

Nuestra sociedad es en extremo violenta, es decir, contraria a la liberación de la realidad, generadora de tensiones, que, tarde o temprano, terminan por dañar

29. I. Ellacurfa, Veinte años de historia en El Salvador (1969-1989). Escritos políticos, I., p. 36.

30. Antonio González F., hrtp://www.servicioskoinonia.org/relat/022.htm 
cualquier tipo de relación interpersonal, y es un signo pésimo de nuestra sociedad el "sentirse indefenso".

El mal se expresa en el ámbito de la libertad, y, en cuanto tal, es un elemento que configura el "mundo", es decir, "influye en la marcha histónica de la humanidad". Es en el "mundo" o "campo de realidad" donde se presentan las cosas, en su buena o mala condición - lo que Ellacuría podrá llamar la "dialéctica de la condición". Ahora bien, esta dialéctica depende de los distintos modos a través de los cuales el mal se inserta en las diferentes sociedades y épocas. Esto significa que la realidad está más allá del bien y del mal. El mal es una condición de lo real respecto del hombre. Por eso, el preguntarse sobre el mal, debe hacerse en el horizonte de la respectividad entre el hombre y la naturaleza".

La cuestión de la agresividad -o agresión - juega un papel importante, en la estructuración de la sociedad entre los animales más desarrollados biológicamente. Los etólogos dicen que este impulso resulta indispensable para la viabilidad de las especies; cuando resulta dañino, los mecanismos inhibitorios frenan dicho impulso. A este proposito, la agresividad es una fuerza de la naturaleza, como tal ambivalente, y en este sentido, positiva y natural. En cualquier caso, la agresividad en el ser humano no debe ser considerada como secuela de ningún pecado. Proviene, sencillamente, de su constitución animal y de su origen evolutivo. Lamentablemente, en el ser humano, la agresividad resulta lujuriosa en cuanto existe un deseo, de por sí, desmesurado, de destrucción: el goce en la destrucción misma, "que se alimenta de lo que destruye"32. Es decir, la agresividad lleva a lo humano al desenfreno. La agresividad es común al animal y al ser humano, pero lo específico del ser humano es que racionaliza ésta. Y de más está recordar el juicio de Ellacuría sobre el uso lujurioso de la violencia, "Yo he mantenido siempre que toda violencia es mala"33.

\section{Epílogo}

De todo lo dicho se deduce que la liberación es un proceso colectivo, en el cual nuestra condición de libres consiste en que todos sean libres para que cada uno pueda ser libre. Ellacuría señala que dicho proyecto requiere de:

31. Hay que decir con Ellacuría (cfr. Teología polírica, San Salvador, 1973), que, cientificamente, es un reduccionismo pretender que la biografía de una persona sea sin más la prolongación lineal de la biología, de igual modo que es un reduccionismo sostener que la historia humana es, sin más, la prolongación lineal de la evolución animal. Un estudio de lo biográfico y de lo histórico, sin embargo, no debe olvidar las ráces biológicas y naturales del ser humano.

32. Teologia politica, p. 57.

33. Ignacio Ellacuria, “Descubrimiento o encubrimiento?”, Revista Senderos, 40 (1992) 110. 
- Objetividad: para acercase a la realidad.

- Realismo: para dar pasos "ajustados" a la realidad.

- Profecia: para denunciar los males a la realidad.

- Utopía: para promover aquello a lo que apunta la negación de los males, y, más allá de ello, al horizonte de plenificación personal y social ${ }^{34}$.

Si el proyecto histórico de liberación se enmarca en la creación libre por el amor cristiano, el resultado es la liberación, que hace posibles la justicia y la libertad como despliegue de lo que el ser humano tiene de participación divina ${ }^{35}$. A esto apunta el amor interesado del que fue testigo Ellacuria, no por ser teólogo de la liberación, sino por seguir la verdad cristiana: encontrar a Jesús donde El dijo que debíamos buscarlo: en las víctimas del mal, en los pobres, latinoamericanos, etc. Siguiendo a J. B. Mez, Ellacuría sería un caso de una "biografía existencial teológica", pues fue asesinado por defender lo que inspiraba su teología.

Esto vale tambien para la filosofía. Su función crítica debe llevamos a una filosofía interesada (parcial, decía Ellacuría, por ser opción por las víctimas del mal), que enfrente desde una perspectiva metafísica el duro proceso de ideologización, que llevan a cabo las ideologras. Así, la filosofía y la cruz llevan a situarse - por opción - en el lugar de los despojados, de los abatidos. Eso es lo que posibilita una filosofía cristiana, porque nos lanza a la cruz como a lo decisivamente cristiano. La locura de la cruz, en su paradoja, pone en cuestión la sabiduría del mundo. La cruz es, entonces, impulso a la búsqueda de la verdad, pero tomada la cruz en su dimensión comunitaria: "fue crucificado con".

Frente a la sensación de desaliento que produce el actual mundo político-económico, los sufrientes cumplen con un papel central, en la propuesta ellacuriana, que, parafraseando a san Ignacio, podría formularse así: ¿qué he hecho para victimizar a tantos seres humanos?, ¿qué hago yo para desvictimizarlos?, y, finalmente, ¿qué debo hacer para que estos seres humanos, hombres y mujeres, sin importar nada más que su condición de víctimas, tengan calidad de vida? De momento, la situación de las víctimas del mal debe suscitar esperanzas y compromisos, "una emotividad dinamizadora [...] a la par de la racionalidad consolidante" ${ }^{\text {"3. }}$.

La indignación debe ser fecunda, en cuanto lleva a una crítica, desde lo que está mal. La responsabilidad de fiscalización compete, por supuesto, a todos, y de ahi que haya que examinar críticamente todos los discursos, los supuestos y

34. Cfr. Ignacio Ellacuría, "Utopía y profetismo", pp. 393-442.

35. "La libertad creadora del hombre es una prolongación de la libertad creadora de Dios y canto más será libre y creadora cuanto prolongue la acción de Dios en la línea del amor." Héclor Samour, "Filosofía y libertad", p. 140.

36. Ignacio Ellacuria, "Subdesamollo y derechos humanos", Revista Latinoamericana de Teologia, 25 (1992) 4. 
la racionalidad que se proponen. El miedo - toda una institución en América Latina - no debe entorpecer esa racionalidad consolidante, que fundamenta la actitud de resistencia - y no de resentimiento- contestataria y solidaria.

Es urgente revertir la "dirección de la historia", dejándonos llevar por Dios, un Dios que es siempre el mismo, pero sin repetirse nunca; que se expresa en fórmulas dogmáticas, pero sin agotarse en ellas. Así, revertir es "redimir" para suscitar una solidaridad transnacional, desde el lugar de los "pobres con espíritu".

Es el momento de pensar la nueva tierra de la utopía cristiana, fundada en la civilización del trabajo. Se trata, ahora sí, de "saber estar en la realidad"37, en y desde la solidaridad y la austeridad. El dinamismo de suidad se ejercita cuando ser libre es donarse a la alteridad personal. Es, como indicó Ellacuría, una proexistencia, esto es, "una vida definitiva por la entrega total a los demás".

Resumiendo desde la perspectiva filosófica, la inteligencia humana tiene que enfrentarse con las cosas reales en cuanto reales, tiene que hacerse cargo de la realidad cognoscitivamente; $y$, al comprenderla situacionalmente, tiene que dar una respuesta adecuada. Que cargue - no que sólo contemple o interprete-con la realidad es el carácter ético de la inteligencia. Y el encargarse de la realidad, remite a la dimensión práxica de ésta, corno crítica creativa de resistencia, que deconstruye la modernidad, que se opone al statu quo y busca su transformación.

La historización de la inteligencia, desde esta perspectiva, hace ver que el nexo entre inteligencia y realidad, entre el ser humano y su mundo, es la historia. Este estar "religado" a la realidad, como decla Zubiri, se da en la historia En consecuencia, la historia también es el lugar de la "obligación" moral. Ellacuría vio esto claramente al escribir no sólo su teología, sino también su ética: "La historia es el lugar de realización ética. La historia no está hecha, se construye, es un proceso de creación de posibilidades humanas, y en tanto que tal, una labor ética" ${ }^{\prime 39}$.

Asf, el problema de las víctimas del mal, puede decirse, no tiene que ver con la fundamentación de sus derechos, sino, ante todo, con un asunto de voluntad ética y política, en cuanto es, inicial y radicalmente, una cuestión que nos compete a todos y cada uno.

Digamos para finalizar: "Esta realidad una es intrínsecamente dinámica. El dinamismo entero de la realidad historica es lo que ha de entenderse como praxis. Esta praxis, así entendida, tiene múltiples formas, tanto por la parte del todo, que en cada caso es su sujeto más propio, como por el modo de acción y el resultado que propicia. Pero en definitiva, la actividad de la realidad histórica es la praxis - liberadora de la realidad creativamente-, entendida como totalidad dinámica"3".

37. Xavier Zubiri, Inteligencia y razón, Madrid, 1983, p. 352.

38. Filosofia..., p. 89.

39. Veinte años de historia..., p. 119. 
Ellacuria soñó con una civilización del trabajo - piedra angular para desarollar la humanidad- para revertir la historia. Una civilización en donde quepan todos y cada uno, y la vida no sea el pretexto, sino el contexto para liberar nuevas formas de realidad, que permitan una sociedad austera y solidaria. 